\title{
FORMAÇÃO DO ACERVO DA ACADEMIA IMPERIAL DE BELAS ARTES E O PAPEL DAS COMISSÕES DE PROFESSORES
}

\author{
FORMACIÓN DEL ACERVO DE LA ACADEMIA \\ IMPERIAL DE BELLAS ARTES (AIBA) Y PAPEL \\ DE LAS COMISIONES DE PROFESORES
}

\author{
Rosani Godoy - godoy.obrasraras@eba.ufrj.br \\ Coordenadora da Biblioteca de Obras Raras da EBA/UFRJ \\ (EBAOR). Mestra em Biblioteconomia pela Universidade Federal do \\ Estado do Rio de Janeiro - UNIRIO. \\ Icléia Thiesen - icleiathiesen@gmail.com \\ Professora Titular da Universidade Federal do Estado do Rio de \\ Janeiro - UNIRIO. Doutora em Ciência da Informação pelo IBICT \\ em convênio com a UFRJ.
}

\begin{abstract}
RESUMO
Introdução: $O$ artigo objetiva demonstrar os processos de formação do acervo da Biblioteca da Academia Imperial de Belas Artes (AIBA), analisando a forma como eram realizadas as aquisições $e$ as providências tomadas, caracterizando o que hoje chamaríamos de "política de aquisição de acervo", pelos dirigentes da AIBA.

Objetivo: Evidenciar o papel das Comissões de Professores no processo de seleção do acervo.

Metodologia: Centrada na leitura, análise de conteúdo e interpretação de fontes primárias, como ofícios e Relatórios Anuais, datados de 1832 a 1888, enviados pelos dirigentes da AIBA ao Ministro da Educação e Instrução Publica, documentos históricos do arquivo do Museu D. João VI, entre outros.

Resultados: Revelam práticas biblioteconômicas sendo realizadas na Biblioteca da AIBA desde o início do século XIX, como a existência de Comissões de Professores que realizavam pareceres sobre as obras a serem incorporadas ao acervo durante o processo de seleção.

Conclusões: A "Política de aquisição", ao que tudo indica, foi bem-sucedida por ter a AIBA investido na aquisição e no incentivo à doação de obras de interesse à formação do artista e ter como selecionadores diretores e secretários, com o apoio de uma Comissão de Professores, formando artistas de renome que representaram a Arte no país.
\end{abstract}


Palavras-chave: Biblioteca da Academia Imperial de Belas Artes (Brasil). Academia Imperial de Belas Artes (Brasil). Seleção.

\section{INTRODUÇÃO}

O presente artigo é fruto de pesquisa de dissertação que tem o intuito de analisar os aspectos históricos do processo de formação do acervo da Biblioteca da Academia Imperial de Belas Artes (AIBA) e que guarda em si a memória institucional do ensino artístico no Brasil, evidenciando sua contribuição para o ensino de Belas Artes desenvolvido na antiga AIBA, no século XIX. Com o advento da República, a Academia passará a chamar-se Escola Nacional de Belas Artes (ENBA) e, a partir de 1971, será denominada Escola de Belas Artes (EBA), da Universidade Federal do Rio de Janeiro, nome que mantém ainda hoje (GODOY, 2015).

A importância do estudo desse acervo se dá, inclusive, pela origem da sua formação, que assinala a vinda da Missão Artística Francesa, em 1816, e consequente fundação da Academia Imperial de Belas Artes, a primeira no Brasil voltada para o ensino oficial. Analisamos a forma como eram realizadas as aquisições $e$ as providências tomadas, visando caracterizar o que hoje chamaríamos de "política de aquisição de acervo", pelos dirigentes da AIBA.

Nesse aspecto, dois personagens se destacam: Felix Emilio Taunay (1795-1881), diretor da Academia de 1834 a 1851 e Manuel de Araujo Porto-alegre (1806-1879), diretor da Academia de 1854 a 1857. As bases sólidas por eles estabelecidas ao administrarem a Biblioteca da Academia permaneceram como base para a administração de futuros diretores da AIBA.

Ressaltamos a importância das Comissões de Professores existentes na Academia desde o princípio do século XIX. Concluímos que a "Política de aquisição do acervo" foi fundamental para o sucesso do ensino da Academia. As aulas ministradas pelos grandes mestres 
que formaram a primeira geração de artistas e que tinham como material de apoio o seleto acervo da Biblioteca foram fundamentais para o sucesso profissional desses artistas. O contato com as obras didáticas da Biblioteca afetou de forma positiva a trajetória de suas vidas, tornando-os artistas de renome.

A pesquisa utilizou-se da literatura e de documentos primários disponíveis em arquivos e bibliotecas, entre os quais o arquivo histórico do Museu D. João VI e do Center for Research Libraries da Universidade de Chicago a fim de compreender como se deu a formação do acervo que hoje constitui a Biblioteca de Obras Raras da Escola de Belas Artes da Universidade do Rio de Janeiro (UFRJ) e justifica-se por contribuir para os estudos sobre a história das bibliotecas, com enfoque na formação, características e relevância do seu acervo. Está de acordo com recomendações da IFLA, através da Library History Section, que incentiva esse tipo de pesquisa em todos os países. Segundo Silva e Mazzuco (2012) na América Latina, onde a presença das bibliotecas já completou mais de 500 anos, a sua história ainda não mereceu a atenção devida.

\section{A ACADEMIA IMPERIAL DE BELAS ARTES (AIBA)}

Não poderíamos falar da Biblioteca da Academia Imperial de Belas Artes sem apresentarmos um breve histórico da sua origem. A AIBA foi criada em 1816, e paralelamente às suas atividades formou uma Biblioteca com um acervo de livros e gravuras valiosos e significativos. O contexto de criação da Academia nos remete ao século XIX. A criação da Academia fazia parte do discurso corrente na época de implantar uma civilização no país, sendo assim, a finalidade dessa instituição exigia a formação de uma biblioteca, dotada de livros que atendessem às necessidades acadêmicas dos mestres e dos alunos. As obras produzidas por eles refletiriam, em dado momento, o contexto de uma época de grandes transformações. 
A criação de instituições culturais é parte do ideário dos oitocentos, constituindo objetivo de todas as nações projetarem-se no concerto das ideias iluministas. Na capital do Império havia grande circulação de ideias vindas da Europa através não apenas do intercâmbio de autoridades e intelectuais que empreendiam viagens de estudos, individualmente ou em comissões oficiais, mas também através da literatura importada do continente europeu (THIESEN, 2008).

Em 1822 a construção da Independência nacional tornou-se uma preocupação do Estado. O passado reconstruído de modo intelectual torna-se uma importante fonte de legitimação do novo regime (PEREIRA, 2012). Segundo Schwarcz (2008), a história conta que a ideia de contratar artistas franceses com certo mérito em seu meio, a fim de emancipar a arte em território brasileiro, surgiu e foi cultivada por Dom Antônio de Araújo de Azevedo, conhecido como Conde da Barca (1752-1817), homem "verdadeiramente sábio e profundamente instruído". Por incentivo do Conde, em 1815, Dom João VI mandou contratar na Europa um grupo de artistas e artífices indispensáveis para fundar, no Rio de Janeiro, uma escola de ciências, artes e ofícios.

O grupo de artistas embarcou no veleiro Calphe, em uma viagem de dois meses, chegando ao Rio de Janeiro em 26 de março de 1816. Podemos afirmar que a Escola Real das Ciências, Artes e Ofícios, futura Academia Imperial de Belas Artes, foi desde o princípio idealizada e formada por homens extremamente cultos, que visavam facilitar 0 progresso da cultura e das artes. A Missão Artística Francesa, liderada por Joachim Lebreton (1760-1819) inicia oficialmente o ensino artístico no país. Apesar de já oficializada, a Escola só começaria a funcionar, de fato, em 1826. O Rio de Janeiro como sede da Corte e Capital do Reino precisou ser moldado para atender às necessidades do Rei, incluindo a criação de estabelecimentos de educação. A Academia Imperial de Belas Artes foi uma das instituições que tiveram papel relevante na construção da cidade, sede da corte e capital do reino. A Biblioteca da AIBA acompanharia todo esse processo de nacionalização, como uma 
instituição singular e atrelada, em todo tempo, à Academia. É o que veremos a seguir.

\section{A BIBLIOTECA DA AIBA: FORMAÇÃO DO ACERVO}

A Biblioteca da AIBA, desde o início, teve um papel de destaque no planejamento da AIBA pela sua localização no projeto original do edifício, desenhado por Grandjean de Montigny. Foi planejada para ocupar o andar superior da sala central, única parte construída no segundo andar do prédio que ainda não havia sido concluído (RIO DE JANEIRO, 6150, 1831-1841).

Com a necessidade da formação de uma biblioteca para dar suporte ao ensino de artes, inicia-se a constituição do acervo sendo formado principalmente com a transferência de livros da Biblioteca Pública Imperial, por doações que começaram com nossos imperadores, somando-se a de professores e suas famílias, a de artistas, a de ministros de Estado, de instituições nacionais e estrangeiras e outros diferentes doadores que tinham como ponto comum o interesse pela preservação da memória artística em benefício da pesquisa acadêmica (LUZ, 1999, p. 150). A importância total arrecadada com as matrículas dos alunos na Academia, abertas no dia 3 de fevereiro de cada ano, também era empregada na compra de livros e estampas para a Biblioteca (MORALES DE LOS RIOS, 1942).

A atividade de seleção efetuada por Felix Emilio Taunay e, posteriormente, por Manuel de Araujo Porto-alegre, foi um diferencial para a formação do acervo, pois ambos eram homens comprometidos com o ensino de Artes da AIBA. O período que corresponde à gestão de ambos os diretores pode ser denominado como o que constituiu 0 acervo-base da Biblioteca, por identificarmos nele seu período fundador e, especialmente, por ter sido formado com o objetivo de servir aos primeiros alunos da Academia. As primeiras obras a integrarem o acervo serviram de apoio para futuras aquisições durante a gestão de outros diretores que viriam a dirigir a AIBA. Quando consideramos as ações de 
Taunay e Porto-alegre no período em que estiveram à frente da AIBA, constatamos que a preocupação de ambos era a de formar um acervo atualizado e útil à Biblioteca.

Taunay, além de traduzir diversas obras, cuidou, desde o tempo em que exerceu o cargo de secretário, de organizar o acervo da Biblioteca. Ambicionava constituir uma Biblioteca que contribuísse para o desenvolvimento das Artes, ou seja, um instrumento para a definitiva formação da identidade do Brasil como um país que viesse a integrar o concerto das nações.

Por diversas vezes, em seus discursos de abertura dos anos letivos, Taunay mencionava a Biblioteca que ia se formando, para seu orgulho e satisfação. No ano de 1835, referia-se ao Ministro de Estado, Sr. Joaquim Vieira da Silva e Souza, "atento à formação da nossa bibliotheca e às suas ações para conseguir da Biblioteca Pública a remessa de exemplares de livros de arte que nela existissem em duplicata" (RIO DE JANEIRO, 6150, 1831-1841, p.116). No ano seguinte, em discurso para alunos e membros da Congregação, elogia o andamento da Academia em relação aos discentes, não deixando de mencionar a Biblioteca, inclusive identificando a sua missão para a época:

Assim se deu principio à bibliotheca, a qual não só nos proporcionará facilidades de estudo e iniciar-vos há na historia das Artes, más também vos será ainda mais útil, porque hé publica; porque com o andar dos tempos tornara geraes certos conhecimentos necessários para julgar as produções dos artistas (RIO DE JANEIRO, $6150,1831-1841$, p. 129).

Taunay adquiriu para a Biblioteca obras como Architecture Toscane, de Grandjean de Montigny, considerada de grande utilidade para o ensino teórico de arquitetura e Flora Fluminensis, de Frei Mariano da Conceição Veloso que representava a cultura nacional, obra de "utilidade nacional", segundo Taunay. 
A Reforma Pedreira, instaurada por Porto-alegre, constituiu um marco no ensino da AIBA. A inclusão de novas disciplinas influenciou, inclusive, na seleção para a aquisição de novas obras que passariam a fazer parte do acervo da Biblioteca. Com o novo método de ensino, criaria os cursos técnicos e, consequentemente, novas disciplinas: Matemáticas Aplicadas e Perspectiva para os jovens artistas e as de Desenho Geométrico e Desenho e Escultura de Ornatos para os industriais (GALVÃO, 1959). Em seu discurso, ao assumir a direção da AIBA, Porto-alegre deixa claro suas intenções patrióticas ao afirmar que chegaria uma época em que o brasileiro apreciaria "mais o criador do que o copista" (GALVÃO, 1959, p. 25).

Nessa época foram acrescentados à Biblioteca os livros mais técnicos e mais algumas gravuras de fauna e flora nacionais para conhecimento dos espécimes da natureza nacional, livros sobre o estudo do corpo humano, fundamental para a pintura histórica e poemas que refletiam uma ação civilizadora (CASTRO, 2007).

Durante o processo de formação do acervo, apesar de muitas dificuldades financeiras, a Biblioteca continua investindo no acervo para torná-lo um instrumento cada vez mais proveitoso no apoio ao ensino de Artes proposto pela AIBA. Vários títulos foram incorporados por compra diretamente da França e também através de livreiros instalados no Rio de Janeiro, com verba da própria Academia. Na concepção de Gomes Júnior (2008)

O "Fundo da Academia" nos faz pensar que nos dezessete anos da gestão de Taunay houve um esforço sistemático para equipar a Biblioteca com livros importantes para o ensino, para o próprio uso de professores, de alunos e, provavelmente, de artistas que gravitavam em torno da Academia.

Para um satisfatório funcionamento a Biblioteca tinha como um dos seus objetivos a eficiência no que podemos denominar, atualmente, de "Política de aquisição" do acervo. Notamos, ao longo da pesquisa, 
que o acervo da Biblioteca da AIBA não foi desenvolvido aleatoriamente, todo o processo de seleção era cuidadosamente analisado. Os professores, ao cumprirem com as exigências do ensino, faziam suas solicitações por meio de listagens de obras relevantes para o ensino, a fim de prepararem os alunos que representariam a Arte no País.

Dentre as obras selecionadas para aquisição estavam incluídas as estampas. Isto porque boa parte da formação do artista estava baseada no exercício continuado da cópia das pinturas da Pinacoteca ou das estampas da Biblioteca, o que não era específico do ensino artístico no Rio de Janeiro, mas característica geral das academias. Como lembra Pevsner (2005 apud GOMES JÚNIOR, 2008) a Academia de Pintura e Escultura francesa, desde o tempo de Le Brun, e até mesmo no século XIX, comportava uma classe elementar e outra superior, as quais se dividiam em três fases do aprendizado: primeiro apenas a cópia de desenhos, pinturas e gravuras ${ }^{1}$, dais quais a AIBA possuía um bom número, depois o desenho a partir de baixos-relevos em moldagem direta em gesso, tomados às escolas clássicas, recomendados ao ensino acadêmico, e esculturas antigas e, por fim, o desenho a partir de modelos vivos (PEVSNER, 2005 apud GOMES JÚNIOR, 2008). Por esta razão a maior parte dos livros pertencentes ao acervo é fartamente ilustrada. Em relação à afirmação de Pevsner, Marize Malta acrescenta que:

Os manuais, didaticamente alicerçados nas estampas depositadas em suas páginas, estão inseridos no bojo das transformações relativas à produção de imagens que ocorreram no século XIX, quantitativas $e$ qualitativas, sendo co-responsáveis no estabelecimento da centralidade da imagem na construção de sentido (...) As gravuras, na sua maioria, não eram apenas ilustrações, mas evidências visuais. O mundo na sua

\footnotetext{
${ }^{1}$ São exemplos a Coleção das loggias do Vaticano, de Giovanni da Udine e Pierino del Vaga, alunos de Rafael; Le guide de l'ornamentiste, de Charles Normand; o Dictionnaire des beauxarts, de A L. Millin, dentre outros.
} 
dimensão histórica e geográfica poderia ser sintetizado em coleções de figuras, estampas, repertórios ornamentais, fazendo-se conhecer por meio da experiência visual (MALTA, 2011, p. 544).

Figura 1 - Detalhe da Loggia (Pilastra XI) de Giovani Ottaviani. Buril/Têmpera/Papel.

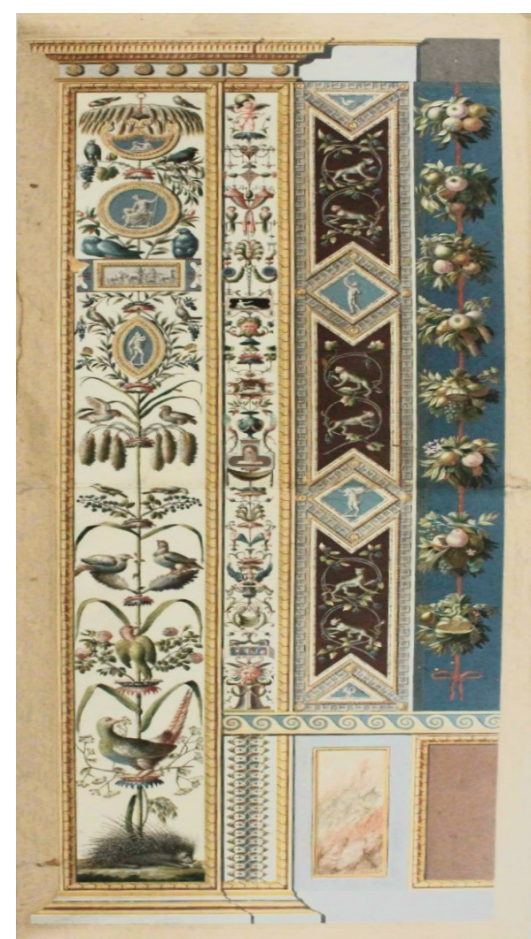

Fonte: Acervo do Museu D. João VI/EBA/UFRJ - Documento no 3451, [18-?] Mapoteca 9. Fotografia de Guilherme Xavier (2015)

O ofício de 30 de agosto de 1855, ao Governo, enviado por Portoalegre enfatiza a importância das estampas que faziam parte do acervo da Biblioteca:

A creação de uma bibliotheca puramente artística, ou depósito de estampas de todos os gêneros, deu à França um imenso resultado industrial com que todos os artistas aí encontram um imenso depósito de originais a consultar. O pintor histórico, o cenógrafo, o estatuário, o arquiteto, o ornamentista, o gravador, e os mesmos artífices, se felicitam de semelhante manancial, que os faz lucrar tempo, despesas e colherem ideas não só nas obras ali expostas, como nas informações que recebem dos empregados da casa [...] (RIO DE JANEIRO, 4343, 1855). 
Pela leitura e análise das Atas, Relatórios, Ofícios e Pareceres da AIBA, conforme tivemos oportunidade de verificar, observamos a existência de Comissões de professores, ou Comissões didáticas, conforme termo utilizado pela diretoria da AIBA como prática utilizada pela Academia, desde a formação de sua Biblioteca. Essas Comissões tinham como função avaliar as obras indicadas, principalmente, pelos professores da AIBA e as que eram oferecidas por livreiros através de catálogos. Entendemos que era imprescindível que os serviços de seleção e aquisição (solicitação de doações e verbas ao Governo para compras) fossem realizados pelo diretor e pelo secretário da Academia, tendo como apoio essas Comissões, pois seus integrantes possuíam grande conhecimento nas Artes. Seus pareceres eram compostos de itens que iam desde o conteúdo das obras, o estado de conservação física, a data da publicação, autenticidade das obras, até o valor solicitado pelos livreiros.

Durante toda a trajetória da Biblioteca da AIBA, mesmo após o período fundador da Biblioteca, observamos a continuidade da prática de atuação de Comissões de Professores e de "Políticas de aquisição" sendo realizadas pela Academia. A escassez dos fundos destinados à AIBA não permitia que o valor disponível para a sua administração fosse desperdiçado com aquisições que não fossem extremamente necessárias ao acervo, outro ponto que ressalta a importância da atividade de seleção.

No Relatório dos Ministros, Sessão Ordinária de 1838, o Ministro e Secretário de Estado Bernardo Pereira Vasconcellos lamentava a situação do pequeno orçamento da Academia que não satisfazia às necessidades decorrentes das novas aulas e do aumento dos preços e objetos indispensáveis ao ensino:

A consignação votada para a Academia das Belas Artes he muito inferior às suas despesas, em razão do estabelecimento das novas aulas, e do aumento no preço dos objetos para 0 ensino. Torna-se indispensável aumentar essa consignação, e 
estabelecer huma quantia para compra de colecções preciosas, que algumas vezes aparecem á venda, e por falta de fundos não podemos obter. (BRASIL, 1837, p.17).

Constatamos que nas reuniões de Congregação da AIBA, discutiam-se diversos assuntos referentes à Biblioteca, inclusive fica aparente o forte interesse demonstrado pelo diretor, secretário e professores da Academia no desenvolvimento do acervo. Como mencionado anteriormente, o diretor e os professores da AIBA tinham o costume de apresentar aos professores membros da Comissão listas desideratas de títulos a serem incluídos na Biblioteca para que fossem emitidos pareceres pelos mesmos. De acordo com Figueiredo (1998), a seleção é um processo de tomada de decisão título a título. De acordo com essa afirmação, esse era um dos motivos da eficiência na escolha das obras a serem incorporadas ao acervo. Os membros da Comissão examinavam minuciosamente cada título, inclusive a condição física da obra, como demonstra o parecer transcrito a seguir referente à obra II costume antico e moderno di tutti a popoli, por Giulio Ferrari:

A Comissão nomeada para examinar a obra intitulada /I costume antico e moderno di tutti a popoli pelo Dr. Julio Ferrari, tem a honra de informar a V. Exc ${ }^{a}$. que esta obra é uma das mais completas que há sobre costumes. [...] Em seo vasto plano comprehende a historia do Governo, milicia, religião, artes, sciencias, e usos de todos os povos do universo, antigos e modernos, tudo provado com os monumentos da antiguidade e representado em 1647 estampas gravadas em aço e quase todas coloridas a aquarella. É pois ella, não só util mas até indispensavel em uma bibliotheca de Bellas-Artes, sendo certo que são os artistas quem mais frequentem e precisão indagar quaes os trajes dos personagens que devem reviver na tela, no marmore, ou sobre o palco. [...] No exemplar que nos foi apresentado falta o $14^{\circ}$ volume da obra, que é a $2^{\mathrm{a}}$ parte do $3^{\mathrm{o}}$ tomo da Europa. Esta obra, que consta de 18 tomos divididos em 23 grandes volumes in-4을 encadernados em 21 , está inteiramente nova, e a sua encadernação é optima. [...] Deos guarde a V.Exci ${ }^{\mathrm{a}}$. - Academia das Bellas-Artes, 24 de outubro de 1874. IIIm. Exm. Sir. Conseleiro Antonio Nicolau Tolentino. 
Dignissimo Director da Academia das Bellas-Artes. [...] Victor Meirelles de Lima. João Maximiano Mafra. E. G. Mor- Maia (RIO DE JANEIRO, 4453, 1874).

Ainda em relação às reuniões de Congregação, as Comissões analisavam também os catálogos enviados à Academia por livreiros estabelecidos no Brasil e na Europa. Dentre essas Livrarias citamos a B. L. Garnier², J. G. Azevedo, H. Lombaerts ${ }^{3}$ (RIO DE JANEIRO, 2417, 1862), Firmin Didot (RIO DE JANEIRO, 2649, 1861) e Luso Brasilleira. Segundo Machado (2008) na década de 1840 o comércio era dominado totalmente por estrangeiros. As lojas de luxo, em mãos dos franceses, estavam estabelecidas sobretudo na rua do Ouvidor, que lembrava um recanto parisiense. Da Europa, algumas Livrarias também apresentavam, constantemente, à Academia catálogos oferecendo livros com o que havia de mais raro, valioso e curioso, como: D. Charnay, Cavalier e Despres, Ângelo Bertola, Bernard Guaritch (Londres) (RIO DE JANEIRO, 4432, 1864), Libraire d'Architecture de Bance (Paris) (RIO DE JANEIRO, 4428, 1862). Ressaltamos que a "venda de livros por catálogos é prática antiga, que remonta aos primórdios do comércio livreiro na Época Moderna" (DEACETO, 2005 apud AZEVEDO, 2008).

A AIBA frequentemente recebia informações vindas da Europa sobre obras que estavam sendo utilizadas no ensino europeu. Também era costume que o Ministério dos Negócios do Império enviasse à Biblioteca impressos que continham documentos e notícias importantes sobre as Belas Artes em diferentes Estados da Europa (RIO DE

${ }^{2}$ Inaugurada em 1845 por Baptiste Leon Garnier, foi a livraria mais importante do Rio de Janeiro no século XIX e início do XX, sendo ponto de encontro de intelectuais da época. Seus preços eram elevados, porém determinados livros só eram possíveis de serem encontrados lá (MACHADO, 2008, p. 45).

${ }^{3} \mathrm{O}$ tipógrafo belga Jean-Baptiste Lombaerts, emigrou para o Rio de Janeiro em 1848. Logo que chegou, inaugurou a Tipografia e Livraria Lombaerts, na rua dos Ouríves, 7, plena zona de influência da rua do Ouvidor. Era essa a tipografia mais conceituada da época e a encadernadora (Ao Missal Lombaerts, nome específico da encadernadora), preferida de D. Pedro II, por seus serviços primorosos. A Lombaerts recebia sempre as últimas novidades de livros franceses (MACHADO, 2008, p. 53). 
JANEIRO, 4382, 1877) e os artistas e ministros que porventura estivessem na Europa também contribuíam com indicações de obras preciosas, lá encontradas, para o ensino na Academia. Como exemplo citamos a obra Les Galeries Publiques de l' Europe que é enviada de Paris por José Marques Lisboa, inspetor intendente das Obras Públicas juntamente com um ofício ao Diretor Porto-alegre, recomendando que colocasse o referido exemplar na Biblioteca da AIBA, já que o mesmo tinha grande aceitação na Europa:

Prevaleço-me para pedir-lhe um favor de colocar na Livraria da nossa Imperial Academia um exemplar, (V.S a recebê-lo-há com este Officio) de uma recente publicação [...] que tem aqui tido mais lisonjeira aceitação (RIO DE JANEIRO, 4920, 1857).

Pelo ofício de 12 de maio de 1890, assinado pelo diretor Ernesto Gomes Moreira Maia fica mais uma vez evidente a preocupação dos dirigentes da Academia em economizar os gastos com aquisições das obras para o acervo. O ofício encaminhado a Benjamin Constant Botelho de Magalhães, Ministro da Instrucção Publica, Correio e Telegraphos justifica a compra de livros diretamente da Europa, como sendo o modo mais econômico de aquisição.

Cidadão Ministro Faleis quão elevado e até muitas vezes exagerado é o preço dos livros no mercado desta Capital e como se póde fazer economias relativamente grandes, fazendo-os vir directamente dos mercados da Europa; entretanto se póde dizer do que é relativo ao material de execução necessário às aulas de uma escola de belas artes. Certo como estou de que levarei a bem que se zele com o maior cuidado o bem emprego do dinheiro publico, peço-vos que me autorizeis a fazer vir daqueles mercados, sempre nos estricto limites das consignações orçamentarias todos os livros e revistas necessários ao aumento da biblioteca desta Academia, assim também 0 fornecimento das aulas no que for imprescindível ao estudo dos alunos, encomendas que farei com prévia aprovação vossa. Por esse modo se conseguirá por certo comprar com maior vantagem para os cofres públicos (RIO DE JANEIRO, 1439, 1890). 
Percebemos, assim, o esforço dos interessados no desenvolvimento do acervo em colaborar com cotações de preços, não só no Brasil, mas também em outros países.

$O$ acervo da Biblioteca da AIBA tinha a necessidade de ser completo o bastante para capacitar o artista na execução de quadros, monumentos, painéis, etc. que fariam parte da representação da construção da civilização brasileira de modo mais fiel possível. Notamos que a intenção do diretor e do secretário não era simplesmente enriquecer a Biblioteca com grande quantidade de livros, mas estimavam a qualidade do conteúdo.

Quanto à análise da autenticidade das obras oferecidas à Academia. O documento 3650 (s.d.) é um exemplo. Nele o Sr. Antonio José Barbosa de Oliveira oferece à AIBA, para possível aquisição, uma coleção de 97 gravuras soltas e um volume da obra Natali's Evangelicae Historiae Imagines. A Comissão nomeada para esta análise conclui que a obra citada possuía autenticidade duvidosa. Somente 38 das gravuras avulsas oferecidas foram aprovadas para compra.

De acordo com o ofício 699 de 28 de outubro de 1916, observamos que, após quase um século da criação da Biblioteca, e já como Escola Nacional de Belas Artes (ENBA) a prática das Comissões ainda permanece, inclusive com alguns dos mesmos critérios de seleção: valor financeiro, atualidade e utilidade aos alunos. Pelo ofício citado verificamos que o Sr. Antonio Nunes Taveira envia uma proposta de venda à diretoria da Academia de diversas obras de arquitetura. Dado o parecer do bibliotecário da ENBA e das Comissões Didática e de Finanças, percebemos assim que os conceitos iniciais de Taunay e Porto-alegre ainda prevaleciam nas decisões do diretor João Batista da Costa, no que diz respeito ao anseio de formar uma biblioteca atualizada e útil: 
Ao Exmo. Dr. A. Soares de Mello, M. D. Diretor Geral da Diretoria do Interior. [...] Informando o requerimento junto, de Antonio Nunes Taveira, propondo vender, á esta Escola, diversas obras antigas, sobre architectura, cumpre-me declarar que, nesta Directoria, apareceu, á 4 de abril do corrente anno, o requerente com a sua proposta e, sendo esta enviada ao Bibliothecario e ás Comissões, didactica e de finanças, foram prestados os seguintes pareceres: "Não temos (informa o Bibliothecario), na nossa biblioteca, os livros constantes da proposta do snr. Antonio Taveira. Muitos deles são raros, como os de Duranõ e o Traité de la Coupe de Pierres, e um deles, Plan Coupé et détails de la Restauration du Palais des Etats et La Nouvelle Salle a Cassal, de Grandjean de Montigny, é particularmente interessante para a nosssa Escola, parecendo-me, entretanto, conveniente a revisão de alguns dos preços propostos".

Os membros da Comissão didática composta pelos professores Araujo Viana, C. Cianconi, Lucilio de Albuquerque e Diogo Chalréo, concordam com o parecer do bibliotecário, inclusive com a revisão dos preços, que julgam "exagerado". De inteiro acordo, a Comissão de finanças composta por Diogo Chalréo e Graça Couto, emite seu parecer enfatizando que, pelo patrimônio da Escola, era impossível adquirir tais obras, porém deixa claro que ao diretor da Escola caberia a decisão final. O diretor se pronuncia da seguinte forma:

Ao meu ver, penso que as referidas obras são oferecidas por preços notavelmente elevados e concordo com o Bibliothecario e com as diversas Comissões que, sobre o assumpto, se manifestaram [...] as referidas obras antigas, oferecidas á venda, não constituem "utilidades praticas, imediatas", para esta Escola, mas méras "curiosidades", aspectos restropectivos, procurados, apenas, por escasso numero de eruditos, não sendo possível perder de vista que trata-se de uma biblioteca meramente escolar, onde as obras didacticas, os livros hodiernos, as revistas, devem necessariamente predominar, para maior utilidade aos estudantes. Seria manifesto erro de administração, adquirir obras de arqueologia, de raríssima consulta, na importância de três contos de reis, quando ainda existem, na nossa pequena biblioteca, sensíveis faltas e lacunas a preencher, em livros modernos, de palpitante actualidade, 
absolutamente indispensáveis ao estudo e consulta dos alunos. (RIO DE JANEIRO, 699, 1916).

Entretanto, no final do parecer, o Diretor afirma que somente abriria exceção para "um pequeno volume de Grandjean de Montigny, por haver sido um dos fundadores desta Escola sendo, entretanto, necessária uma redução no preço de duzentos mil reis" (RIO DE JANEIRO, 699, 1916).

De acordo com Miranda (1980, p. 65 apud Weitzel, 2006, p. 23) "No período anterior à década de 1980 a maioria dos casos de seleção em Bibliotecas Universitárias limitava-se ao rotineiro processo de aquisição a partir de listas preparadas por professores, sem qualquer ingerência do especialista de Biblioteconomia no processo decisório." No caso da Academia, o sucesso na aquisição de livros que realmente atendessem às suas necessidades era devido a um importante fato: ter tido diretores e professores interessados, e com muitas qualidades para desempenhar essas funções. Corroborando com esta afirmação citamos o estudo realizado por Denise Gonçalves, em 1997 e 1998, que constitui um inventário dos livros referentes ao estudo de arquitetura, pertencentes ao acervo da Biblioteca de Obras Raras da Escola de Belas Artes da UFRJ. Este estudo nos informa da importância do conjunto bibliográfico desenvolvido em meados do século XIX, adquiridas a partir da Reforma Pedreira em 1855 e passível de inúmeras possibilidades de exploração do material, ainda constituindo um instrumento para se avaliar o próprio ensino de arquitetura ministrado pela Academia Imperial de Belas Artes. Segundo Denise Gonçalves:

Pudemos observar, e isto deve ser enfatizado, que o conjunto inventariado é da maior importância, reunindo títulos que podem ser encontrados hoje nas principais bibliotecas de língua francesa, o que mostra o cuidado com que foram escolhidos no momento de sua aquisição. (GONÇALVES, 2010, p. 45). 


\section{CONCLUSÃO}

A consolidação do processo de formação do acervo da Biblioteca da AIBA teve a imprescindível participação de Felix Emilio Taunay e Manuel de Araujo Porto-alegre. Ambos se destacaram em todo o processo, sendo eles os responsáveis pela composição do acervo-base, apoiados pelas Comissões de Professores da Academia. As ações de Taunay e Porto-alegre nortearam os futuros dirigentes da AIBA que deram prosseguimento aos serviços de seleção e aquisição. $O$ interesse e a capacidade administrativa desses dois dirigentes foram fatores que contribuíram para a formação de um acervo útil e eficaz na formação do artista.

As Comissões de Professores eram responsáveis pela elaboração de pareceres das obras a serem adquiridas pela AIBA, através do exame das listas desideratas e catálogos oferecidos por livreiros estabelecidos no Brasil e na Europa.

Embora não necessariamente declarada, existia uma "política de aquisição" implícita realizada na Biblioteca da AIBA. Os critérios de seleção observados foram influenciados por diversos fatores, tais quais: atualidade e autenticidade da obra, conteúdo didático e valor financeiro. A análise de documentos primários produzidos no século XIX permitiu identificar essa experiência inovadora para a época, cujo conhecimento não se encontra acessível em outras fontes de estudos. A interdisciplinaridade se confirma como o caminho promissor para a confluência dos estudos históricos com campos de disciplinas profissionais, como a Biblioteconomia, a Arquivística e a Museologia, hoje buscando firmarem-se como instituições de pesquisa, enriquecendo as bases para a reconstrução da memória institucional produzida nos oitocentos, bem como da história da organização do conhecimento no Brasil. 


\section{REFERÊNCIAS}

AZEVEDO, Fabiano Cataldo. Contributo para o perfil do público leitor do Real Gabinete Português de Leitura (1837-1847). Ci. Inf., Brasília, v. 37, n. 2, p. 20-31, maio/ago. 2008. Disponível em:

<http://www.scielo.br/pdf/ci/v37n2/a02v37n2.pdf>. Acesso em: 16 mar. 2014.

BRASIL. Ministério dos Negócios do Império. Relatório anual, 1837. Assunto: Relatórios. Disponível em: <http://wwwapps.crl.edu/brazil/provincial>. Acesso em: 21 jun. 2013.

CASTRO, Isis Pimentel de. Os pintores de história: a relação entre arte e história nas telas de batalhas de Pedro Américo e Victor Meirelles. 2007. 178 f. Dissertação. (Mestrado em História Social) - Instituto de Filosofia e Ciências Sociais, Universidade Federal do Rio de Janeiro, Rio de Janeiro.

FIGUEIREDO, Nice Menezes de. Desenvolvimento \& avaliação de coleções. 2.ed. rev. e atual. Rio de Janeiro: Thesaurus, 1998.

GALVÃO, Alfredo. Manuel de Araujo Pôrto-Alegre: sua influência na Academia Imperial das Belas Artes e no meio artístico do Rio de Janeiro. Revista do Patrimônio Histórico e Artístico Nacional, Rio de Janeiro, p. 19-120, 1959.

GODOY, Rosani Parada. Processos de formação do acervo da Biblioteca da Academia Imperial de Belas Artes e seu uso como material didático (1834-1857). 2015. 187 f. Dissertação (Mestrado Profissional em Biblioteconomia) - Centro de Ciências Humanas e Sociais, Universidade Federal do Estado do Rio de Janeiro, Rio de Janeiro.

GONÇALVES, D. Modelos para o ensino de arquitetura: a coleção de obras raras do Museu D. João VI. In: MALTA, Marize (Org.). 0 ensino artístico, a história da arte e o museu D. João VI. Rio de Janeiro: EBA/UFRJ, 2010. p. 44-50.

GOMES JÚNIOR, G. S. Biblioteca de arte. Circulação internacional de modelos de formação. Novos estudos CEBRAP, São Paulo, n.81, jul. 2008. Disponível em:

<http://www.scielo.br/scielo.php?script=sci_arttext\&pid=S0101$33002008000200012 \&$ lng=pt\&nrm=iso\&tlng=pt>. Acesso em: 12 jul. 2012.

LUZ, Angela Ancora. A Escola de Belas Artes - uma história da arte. Arquivos da Escola de Belas Artes. Rio de Janeiro: EBA/UFRJ, 1999. p.71-91. 
MACHADO, Ubiratan. Pequeno guia histórico das livrarias

brasileiras. São Paulo: Ateliê Editorial, 2008.

MALTA, M. Aprender a ver: modelos para o decorativo nas Obras Raras do Museu D. João VI. In: COLÓQUIO DO COMITÊ BRASILEIRO DE HISTÓRIA DA ARTE, 31., 2011, Campinas. Anais... Campinas: Universidade Estadual de Campinas, 2011.

MORALES DE LOS RIOS FILHO, Adolfo. O Ensino Artístico: subsídios para a sua história. Rio de Janeiro: Imprensa Nacional, 1942.

PEREIRA, Sônia Gomes. Revisão historiográfica da arte brasileira do século XIX. Revista ieb, São Paulo, n. 54, p. 87-106, set.-mar. 2012. Disponível em:

<http://www.revistas.usp.br/rieb/article/view/49114/53192>. Acesso em: 4 fev. 2015.

RIO DE JANEIRO. Universidade Federal do Rio de Janeiro. Ata 6150, 1831-1841. Assunto: Reformas dos Estatutos da Academia e ofícios das reuniões de congregação. Disponível em:

$<$ http://www.docvirt.com/docreader.net/docreader.aspx?bib=MuseuDJoa oVI\&pasta=Avulsos\&pesq=>. Acesso em: 7 fev. 2013.

RIO DE JANEIRO. Universidade Federal do Rio de Janeiro. Ofício 699, de 28 de outubro de 1916. Assunto: Parecer do Bibliotecário e das Comissões didáticas e de finanças. Disponível em:

$<$ http://www.docvirt.com/docreader.net/docreader.aspx?bib=MuseuDJoa oVI\&pasta=Avulsos\&pesq=4438>. Acesso em: 17 de ago. 2015.

RIO DE JANEIRO. Universidade Federal do Rio de Janeiro. Ofício 1439, 27 de maio de 1890. Assunto: Autorização para a vinda de livros. Disponível em:

$<$ http://www.docvirt.com/docreader.net/docreader.aspx?bib=MuseuDJoa oVI\&pasta=Avulsos\&pesq=>. Acesso em: 5 out. 2013.

RIO DE JANEIRO. Universidade Federal do Rio de Janeiro. Ofício 2417, 10 de junho de 1862. Assunto: Nota de compra da Livraria de B. L. Garnier. Disponível em: $<$ http://www.docvirt.com/docreader.net/docreader.aspx?bib=MuseuDJoa oVI\&pasta=Avulsos\&pesq=4438 >. Acesso em: 5 out. 2013.

RIO DE JANEIRO. Universidade Federal do Rio de Janeiro. Ofício 2649, 26 de fevereiro de 1861. Assunto: Nota de compra da Firmin Didot. Disponível em:

<http://www.docvirt.com/docreader.net/docreader.aspx?bib=MuseuDJoa oVI\&pasta=Avulsos\&pesq=4438>. Acesso em: 12 dez. 2014. 
RIO DE JANEIRO. Universidade Federal do Rio de Janeiro. Ofício 3650, [s.d.]. Assunto: Sr. Antonio José Barbosa de Oliveira oferece à AIBA, para possível aquisição, uma coleção de 97 gravuras soltas e um volume da obra Natali's Evangelicae Historiae Imagines. Disponível em: $<$ http://www.docvirt.com/docreader.net/docreader.aspx?bib=MuseuDJoa oVI\&pasta=Avulsos\&pesq=4438>. Acesso em: 5 maio 2015.

RIO DE JANEIRO. Universidade Federal do Rio de Janeiro. Ofício 4343, 30 de agosto de 1855. Assunto: Criação da biblioteca. Disponível em:

<http://www.docvirt.com/docreader.net/docreader.aspx?bib=MuseuDJoa oVl\&pasta=Avulsos\&pesq=>. Acesso em: 19 jun. 2012.

RIO DE JANEIRO. Universidade Federal do Rio de Janeiro. Ofício 4382, 8 de maio 1877. Assunto: Notícias da Europa. Disponível em: $<$ http://www.docvirt.com/docreader.net/docreader.aspx?bib=MuseuDJoa oVI\&pasta=Avulsos\&pesq=>. Acesso em: 2 fev. 2015.

RIO DE JANEIRO. Universidade Federal do Rio de Janeiro. Ofício 4428, 20 de maio de 1862. Assunto: Relação livros e estátuas de gesso encomendada pela Academia Imperial de Bellas Artes. Disponível em: $<$ http://www.docvirt.com/docreader.net/docreader.aspx?bib=MuseuDJoa oVI\&pasta=Avulsos\&pesq=4438>. Acesso em: 5 out. 2013.

RIO DE JANEIRO. Universidade Federal do Rio de Janeiro. Ofício 4432, 25 de março de 1864. Assunto: Rascunho da relação de obras do catálogo que resume o que há de mais raro, valiosos e curiosos dos livros que estão na livraria de Mr. Guaritch. Disponível em $<$ tttp://www.docvirt.com/docreader.net/docreader.aspx?bib=MuseuDJoa oVI\&pasta=Avulsos\&pesq=4438>. Acesso em: 6 fev. 2015.

RIO DE JANEIRO. Universidade Federal do Rio de Janeiro. Ofício 4453, 24 de outubro de 1874. Assunto: Parecer. Disponível em: $<$ http://www.docvirt.com/docreader.net/docreader.aspx?bib=MuseuDJoa oVl\&pasta=Avulsos\&pesq=>. Acesso em: 15 out. 2013.

RIO DE JANEIRO. Universidade Federal do Rio de Janeiro. Ofício 4920, 22 de dezembro de 1857. Assunto: Ofício de José Marques Lisboa, inspetor intendente das Obras Públicas, ao diretor da Academia, remetendo o abono de aproveitamento do pensionista Vítor Meireles de Lima, e comunicando a remessa da publicação "Les Galeries Publiques de l'Europe". Disponível em:

$<$ http://www.docvirt.com/docreader.net/docreader.aspx?bib=MuseuDJoa oVI\&pasta=Avulsos\&pesq=4438>. Acesso em: 11 dez. 2014.

SCHWARCZ, Lilia Moritz. 0 sol do Brasil. São Paulo: Companhia das Letras, 2008. 
SILVA, Sérgio Almeida da; MAZZUCO, Neiva Gallina. História e políticas de educação no Brasil império. In: SEMINÁRIO NACIONAL ESTADO E POLITICAS SOCIAIS NO BRASIL, 2., 2005, Cascavel (PR), Anais eletrônicos... Cascavel. Disponível em: <http://cacphp.unioeste.br/projetos/gpps/midia/seminario2/poster/educacao/pedu15 .pdf>. Acesso em: 5 nov. 2012.

THIESEN, Icléia. Inteligência informacional: revisitando a informação na história. In: ENCONTRO NACIONAL DE PESQUISA EM CIÊNCIA DA INFORMAÇÃO, 9, 2008. São Paulo, Anais eletrônicos... São Paulo, USP, 2008. Disponível em:

$<$ http://enancib.ibict.br/index.php/enancib/ixenancib/paper/viewFile/2988/ 2114>. Acesso em: $10 \mathrm{dez} .2014$.

WEITZEL, Simone da Rocha. Elaboração de uma política de desenvolvimento de coleções em bibliotecas universitárias. Rio de Janeiro: Interciência, 2006.

\section{Title}

Formation of the collection of "Academia Imperial de Belas Artes" and the role of the didactic comissions

\section{Abstract}

Introduction: This article aims to demonstrate the processes of formation of "Biblioteca da Academia Imperial de Belas Artes" (AIBA). We will analyze the way the acquisitions were realized and the actions taken, aiming to characterize what today we would call "policies for collection acquisition", by the leader of AIBA.

Objective: To make evident the role of the Didactic Commissions in the process of collection acquisition.

Methodology: Highlighting on the read, analyze of the content and interpretation of primary sources like Annual Reports, of 1832 a 1888, sent by the leader of AIBA to the Secretary of Education and Public Instruction, in the historic documents of the file in the "Museu D. João VI", among others.

Results: Reveals the existence of library science practices being realized in the Library of AIBA since the beginning of the 19th century like was observed the existence of Didactic Commissions that used to realize the opinions of the books and pictures to be part of the collections in the process of acquisition.

Conclusions: The "Policies of acquisition", to all appearances, was well succeed for having the AIBA investing in the acquisition and in the encouraging to donate books and pictures that were interesting to the formation of the artist and have as selectors the directors and secretaries, with the support of one 
Didactic Commissions, making renowned artists that represented the Art in the country.

Keywords: Biblioteca da Academia Imperial de Belas Artes (Brazil). Academia Imperial de Belas Artes (Brazil). Selection.

\section{Título}

Formación del acervo de la Academia Imperial de Bellas Artes y papel de las comisiones de profesores

\section{Resumen}

Introducción: Este artículo tiene el objetivo de mostrar los procesos de formación del acervo de la Biblioteca de la Academia Imperial de Bellas Artes (AIBA), analizando cómo los dirigentes de la AIBA realizaban adquisiciones y tomaban providencias, un proceso equivalente a lo que hoy llamamos Política de Adquisición de Acervo.

Objetivo: Poner en evidencia el papel de las Comisiones de Profesores en el proceso de selección del acervo.

Metodología: La metodología de estudio para la elaboración de este artículo fue centrada en la lectura, análisis e interpretación de fuentes primarias, tales como oficios e informes anuales enviados por los dirigentes de la AIBA al ministro de Educación e Instrucción Pública entre 1832 y 1888, así como documentos históricos del Museo D. João VI, entre otros.

Resultados: Los resultados de este estudio revelan las prácticas de adquisición llevadas a cabo en la Biblioteca de la AIBA desde inicios del siglo XIX y la existencia de comisiones de profesores que, durante el proceso de selección, daban pareceres sobre la adquisición de obras para el acervo.

Conclusión: La Política de Adquisiciones, según todos los indicios, fue exitosa porque la AIBA invirtió en la adquisición y en el fomento a la donación de obras de interés para la formación del artista, así como al hecho de que la selección de dichas obras estaba a cargo de directores y secretarios con el apoyo de una comisión de profesores, lo que resultó en la formación de artistas que representaron al arte en el país.

Palabras claves: Biblioteca de la Academia Imperial de Bellas Artes (Brasil). Academia Imperial de Bellas Artes (Brasil). Selección.

Recebido em: 10.10 .2015

Aceito em: 20.12.2015 